\title{
Taguchi versus full factorial design to determine the equation of impact forces produced by water jets used in sewer cleaning
}

\author{
Nicolae Medan ${ }^{1, *}$, Mircea Lobontiu ${ }^{1}$, Sandor Ravai Nagy ${ }^{1}$ and Gergely Dezsö ${ }^{2}$ \\ ${ }^{1}$ Technical University of Cluj-Napoca, Department of Engineering and Management of Technology, \\ Victor Babes 62A, Baia Mare, Romania \\ ${ }^{2}$ University of Nyiregyhaza, Department of Physics and Production Engineering, Sóstói 31/B, \\ Nyiregyhaza, Hungary
}

\begin{abstract}
The regular cleaning up of the materials deposed in sewer networks is realised with equipment that uses pressure water jets. The functioning of this equipment is dependent on certain process parameters that can vary, causing variations of the impact forces. The research method of this study is the experiment. The purpose of this study is to determine the equation of impact forces produced by water jets in two ways: once using the Taguchi design of experiments and secondly using the full factorial design of experiments. For the experimental determination of the impact forces a stand for generating water jets and a device for measuring the impact forces are used. Finally, an analysis of the advantages and disadvantages of the two methods used is presented.
\end{abstract}

\section{Introduction}

Phenomena that occur in the cleaning water jets are complex. Adler [1] describes mechanisms occurring at the impact of a jet with a surface. Leach et al [2], Leu et al [3] and Guha et al [4] analysed pressure distribution along the centreline of the water jet.

The aim of this paper is to determine the equation of impact forces produced by water jets from the sewerage system cleaning head, impact forces that depend on the process parameters. The research method of this study is the experiment.

To determine the equation of impact forces produced by water jets are used two type of design of experiment: once using the Taguchi design of experiments and secondly using the full factorial design of experiments.

To measure the impact forces between the water jet and a flat and rigid surface, a stand for generating pressure water jets, as well as a device to measure the impact forces have been designed and built. In the measurements, water jets using pressure between 100 and 200 bars have been used. The values of these pressures correspond to low pressure water jets [5].

\footnotetext{
*Corresponding author: nicolae.medan@,cunbm.utcluj.ro
} 


\section{Equipment used and methodology of the measurements}

To measure the impact forces between the water jet and a flat and rigid surface, a stand for generating pressure water jets, as well as a device to measure the impact forces were designed and built [6].

\subsection{The stand to generate pressure water jet}

Schematic diagram of the stand to generate a pressure jet is shown in Figure 1.

The component parts of the stand are: 1) electric motor 2) flexible coupling; 3) high pressure pump, 4) pressure regulator, 5) pressure gauge, 6) nozzle, 7) tap water, 8) water tank, 9) chassis. Water coming out of the high-pressure pump (3) goes into the pressure regulator (4). The pressure regulator adjusts the pressure and flow of the water in the path of the high-pressure water. This pressure corresponds to the one at the outlet of the nozzle.

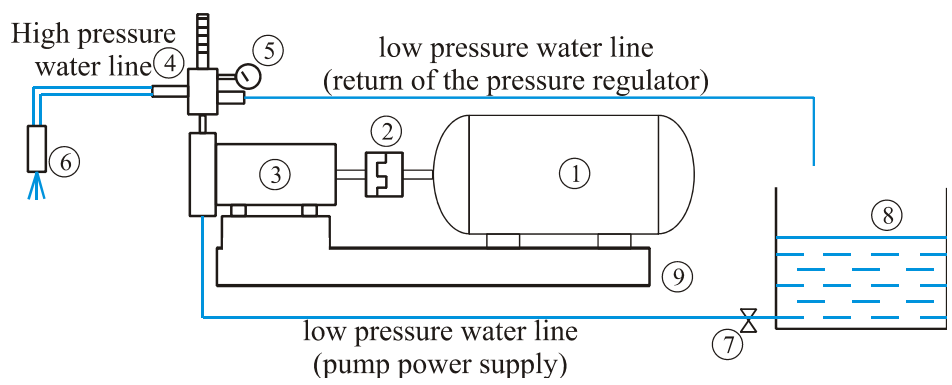

Fig. 1. Diagram of the stand to generate pressure jet.

\subsection{The device to measure the impact forces}

Figure 2 represents the principle diagram of the device for the measurement of the impact force between the water jet and a flat and rigid surface.

The main component parts of the device are:1) high-pressure water hose, 2) support nozzle, 3) nozzle block, 4) nozzle, 5) water jet, 6) flat and rigid target plate, 7) collection path water, 8) scaled container, 9) piezoelectric sensor mounting, 10) piezoelectric sensor, 11) data acquisition Personal Daq/3000, 12) computer for the processing of data; 13) support plate, 14) acrylic tube, 15) rods for adjusting distance $\mathrm{x}$.

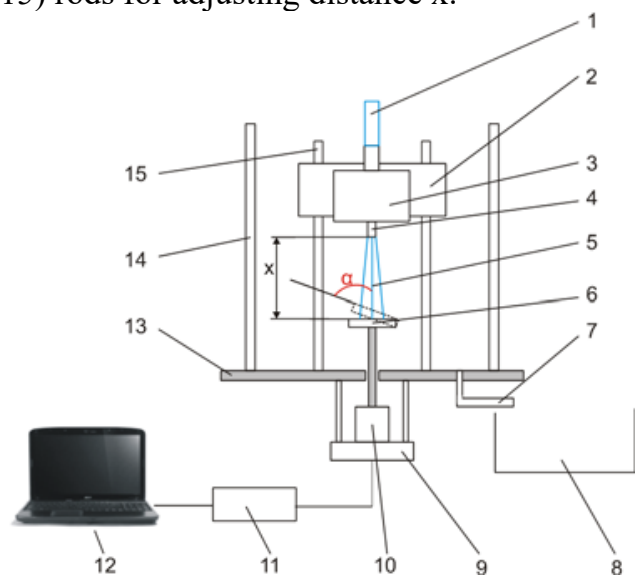

Fig. 2. Diagram of the device for the measurement of the impact force of the water jet. 


\subsection{The process parameters}

In the water jet cleaning process a series of parameters are involved [5]. These parameters can be divided into two major groups, namely: 1) target parameters which shall be defined according to the contact area between the water jet and the surface to be cleaned and 2) process parameters. In the measurement of the impact forces of a stationary water jet and flat and rigid surface the process parameters are involved (figure 3).

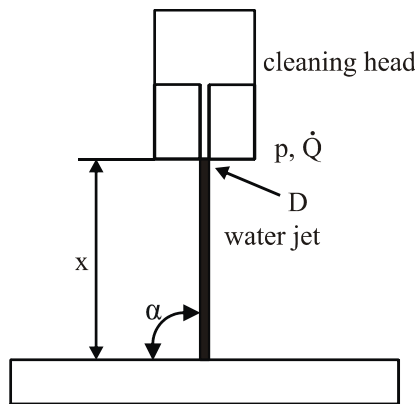

Fig. 3. Process parameters.

They can be divided into two groups, namely hydraulic parameters and the performance parameters. Hydraulic parameters characterized by the system's high pressure pump-nozzle are represented by work pressure (p), volume flow $(\dot{Q})$ and nozzle diameter (D). The performance parameters are more related to the process performance and include the following: cleaning distance $(\mathrm{x})$, impact angle $(\alpha)$ and traverse rate $\left(\mathrm{v}_{\mathrm{T}}\right)$. For a stationary water jet $\mathrm{v}_{\mathrm{T}}=0 \mathrm{~m} / \mathrm{s}$.

\subsubsection{The values of the used parameters}

In table 1 are presented the values of parameters for Taguchi and full factorial methods.

For Taguchi method, each parameter has 2 values, the minim and the maxim, in concordance with the experimental domain. For full factorial method, each parameter is assigned all the values set in experimental field [7].

Table 1. The values of the parameters for Taguchi and full factorial methods.

\begin{tabular}{|l|c|c|c|}
\hline \multirow{2}{*}{\multicolumn{1}{|c|}{ Parameter }} & \multicolumn{2}{|c|}{ Taguchi } & Full factorial \\
\cline { 2 - 4 } & Value 1 & Value 2 & Values \\
\hline Nozzle diameter D [mm] & 1 & 2 & $1,1.5,2$ \\
\hline Pressure $\mathrm{p}[\mathrm{bar}]$ & 100 & 200 & $100,120,140,160,180,200$ \\
\hline Impact angle $\left.\alpha{ }^{0}\right]$ & 60 & 90 & $60,75,90$ \\
\hline Distance $\mathrm{x}[\mathrm{mm}]$ & 25 & 200 & $25,50,75,100,125,150,175,200$ \\
\hline
\end{tabular}

Based on the parameters established in accordance with Table 1 the impact forces were determined. For each experiment was performed three measures of impact force and still it has worked with $\mathrm{F}_{\text {med }}$, representing the arithmetic average of the three forces measured.

For Taguchi method results 16 experiments and a total of 48 measurements. For full factorial method results. For full factorial method results 144 experiments and a total of 432 measurements.

For brief of this paper, we dare not to present the table with the values of $F_{\text {med }}$ obtained, for the two used methods (Taguchi and full factorial). 


\section{Results}

For determine the equation of impact forces, in the first step it is necessary to determine the contribution of each parameter and their interactions.

\subsection{Contribution of parameters and their interactions}

Using the Taguchi method and full factorial method has conducted an analysis of the variance to determine the influence of each parameter and their interactions on the impact force. In Table 2 is presented the analysis of the variance, using Minitab 17.

Table 2. Analysis of Variance (Taguchi method and full factorial method).

\begin{tabular}{|l|c|c|c|c|}
\hline \multirow{2}{*}{ Source } & \multicolumn{2}{c|}{$\begin{array}{c}\text { DF } \\
\text { (degree freedom) }\end{array}$} & \multicolumn{2}{c|}{ Contribution } \\
\cline { 2 - 5 } & Taguchi & Full factorial & Taguchi & Full factorial \\
\hline Regression & 10 & 10 & $99.76 \%$ & $99.14 \%$ \\
\hline Diameter (A) & 1 & 1 & $64.38 \%$ & $71.32 \%$ \\
\hline Pressure (B) & 1 & 1 & $22.71 \%$ & $18.05 \%$ \\
\hline Angle (C) & 1 & 1 & $2.84 \%$ & $3.63 \%$ \\
\hline Distance (D) & 1 & 1 & $0.54 \%$ & $0.24 \%$ \\
\hline Diameter*Pressure & 1 & 1 & $7.63 \%$ & $4.63 \%$ \\
\hline Diameter* Angle & 1 & 1 & $1.04 \%$ & $0.93 \%$ \\
\hline Diameter* Distance & 1 & 1 & $0.08 \%$ & $0.09 \%$ \\
\hline Pressure*Angle & 1 & 1 & $0.42 \%$ & $0.24 \%$ \\
\hline Pressure*Distance & 1 & 1 & $0.07 \%$ & $0.01 \%$ \\
\hline Angle*Distance & 1 & 1 & $0.04 \%$ & $0.00 \%$ \\
\hline Error & 421 & 5 & $0.24 \%$ & $0.86 \%$ \\
\hline Total & 431 & 15 & $100 \%$ & $100 \%$ \\
\hline
\end{tabular}

From table 2 results that 3 parameters (diameter, pressure, angle) and 2 interactions (diameter*pressure and diameter*angle) have a significant contribution to the impact forces in both cases Taguchi method and full factorial method.

\subsection{Equation of impact forces}

Based on the results obtains in table 2, was determined the equation of impact forces in both cases Taguchi method and full factorial method.

Using Minitab 17, the equation (1) of impact forces for Taguchi method was determined

$$
F_{\text {Taguchi }}=23.0-33.6 \cdot A-0.2101 \cdot B \cdot 0.254 \cdot C+0.2992 \cdot A \cdot \mathrm{B}+0.375 \cdot A \cdot C
$$

Using Minitab 17, the equation (2) of impact forces for full factorial method was determined:

$$
F_{\text {full fact. }}=22.91-32.97 \cdot A 0.2088 \cdot B-0,26 \cdot C+0.30072 \cdot A \cdot \mathrm{B}+0.3755 \cdot A \cdot C
$$

\subsection{Comparison between the two equations determined}

To compare the accuracy of two equations determined using Taguchi and full factorial designs of experiment, in table 3 are presented the impact forces measured. Was used the values of the parameters for full factorial methods, less the parameter distance, who was fixed at $50 \mathrm{~mm}$ (the influence of this parameter it is insignificant).

It was calculated relative error of the force measured and calculated force $\mathrm{F}_{\text {Taguchi }}$. Also, was calculated relative error of the force measured and calculated force $\mathrm{F}_{\text {full factorial. }}$. 
Table 3. Measured and calculated impact forces. Relative errors.

\begin{tabular}{|c|c|c|c|c|c|c|c|c|}
\hline \multirow{2}{*}{$\begin{array}{l}\text { Exp. } \\
\text { No. }\end{array}$} & \multirow{2}{*}{$\begin{array}{l}\text { Diameter } \\
{[\mathrm{mm}]}\end{array}$} & \multirow{2}{*}{$\begin{array}{c}\text { Pressure } \\
\text { [bar] }\end{array}$} & \multirow{2}{*}{$\begin{array}{c}\text { Angle } \\
{[\alpha]}\end{array}$} & \multirow{2}{*}{$F_{\text {det }}$} & \multirow{2}{*}{$\mathrm{F}_{\text {taguchi }}$} & \multirow{2}{*}{ Ffull } & \multicolumn{2}{|c|}{ Relative error $\varepsilon_{x}[\%]$} \\
\hline & & & & & & & FTaguchi & $F_{\text {full factorial }}$ \\
\hline 1 & 1 & 100 & 60 & 6.59 & 6.51 & 6.06 & 1.24 & 7.98 \\
\hline 2 & 1 & 100 & 75 & 8.49 & 8.34 & 7.80 & 1.83 & 8.17 \\
\hline 3 & 1 & 100 & 90 & 9.95 & 10.16 & 9.53 & 2.13 & 4.23 \\
\hline 4 & 1 & 120 & 60 & 8.48 & 8.29 & 7.90 & 2.17 & 6.75 \\
\hline 5 & 1 & 120 & 75 & 10.54 & 10.12 & 9.64 & 4.04 & 8.61 \\
\hline 6 & 1 & 120 & 90 & 11.83 & 11.94 & 11.37 & 0.96 & 3.91 \\
\hline 7 & 1 & 140 & 60 & 9.04 & 10.07 & 9.74 & 11.46 & 7.80 \\
\hline 8 & 1 & 140 & 75 & 11.24 & 11.90 & 11.47 & 5.84 & 2.06 \\
\hline 9 & 1 & 140 & 90 & 12.60 & 13.73 & 13.21 & 8.91 & 4.79 \\
\hline 10 & 1 & 160 & 60 & 11.41 & 11.86 & 11.58 & 3.94 & 1.53 \\
\hline 11 & 1 & 160 & 75 & 14.18 & 13.68 & 13.31 & 3.52 & 6.12 \\
\hline 12 & 1 & 160 & 90 & 15.25 & 15.51 & 15.05 & 1.73 & 1.31 \\
\hline 13 & 1 & 180 & 60 & 13.54 & 13.64 & 13.42 & 0.73 & 0.87 \\
\hline 14 & 1 & 180 & 75 & 15.09 & 15.46 & 15.15 & 2.50 & 0.44 \\
\hline 15 & 1 & 180 & 90 & 16.55 & 17.29 & 16.89 & 4.45 & 2.00 \\
\hline 16 & 1 & 200 & 60 & 15.51 & 15.42 & 15.26 & 0.57 & 1.61 \\
\hline 17 & 1 & 200 & 75 & 17.03 & 17.25 & 16.99 & 1.29 & 0.21 \\
\hline 18 & 1 & 200 & 90 & 18.25 & 19.07 & 18.72 & 4.51 & 2.60 \\
\hline 19 & 1.5 & 100 & 60 & 15.95 & 15.92 & 15.88 & 0.20 & 0.45 \\
\hline 20 & 1.5 & 100 & 75 & 20.18 & 20.56 & 20.43 & 1.91 & 1.25 \\
\hline 21 & 1.5 & 100 & 90 & 24.23 & 25.20 & 24.98 & 4.02 & 3.09 \\
\hline 22 & 1.5 & 120 & 60 & 21.23 & 20.69 & 20.73 & 2.52 & 2.37 \\
\hline 23 & 1.5 & 120 & 75 & 25.09 & 25.34 & 25.28 & 0.98 & 0.74 \\
\hline 24 & 1.5 & 120 & 90 & 28.3 & 29.98 & 29.82 & 5.93 & 5.39 \\
\hline 25 & 1.5 & 140 & 60 & 23.83 & 25.47 & 25.57 & 6.87 & 7.31 \\
\hline 26 & 1.5 & 140 & 75 & 29.64 & 30.11 & 30.12 & 1.59 & 1.62 \\
\hline 27 & 1.5 & 140 & 90 & 32.77 & 34.75 & 34.67 & 6.05 & 5.80 \\
\hline 28 & 1.5 & 160 & 60 & 29.01 & 30.24 & 30.42 & 4.25 & 4.86 \\
\hline 29 & 1.5 & 160 & 75 & 35.22 & 34.88 & 34.97 & 0.95 & 0.72 \\
\hline 30 & 1.5 & 160 & 90 & 37.74 & 39.53 & 39.52 & 4.73 & 4.71 \\
\hline 31 & 1.5 & 180 & 60 & 33.29 & 35.02 & 35.27 & 5.19 & 5.93 \\
\hline 32 & 1.5 & 180 & 75 & 40.88 & 39.66 & 39.81 & 2.99 & 2.61 \\
\hline 33 & 1.5 & 180 & 90 & 43.81 & 44.30 & 44.36 & 1.12 & 1.26 \\
\hline 34 & 1.5 & 200 & 60 & 37.34 & 39.79 & 40.11 & 6.56 & 7.42 \\
\hline 35 & 1.5 & 200 & 75 & 45.36 & 44.43 & 44.66 & 2.04 & 1.54 \\
\hline 36 & 1.5 & 200 & 90 & 48.62 & 49.07 & 49.21 & 0.93 & 1.21 \\
\hline 37 & 2 & 100 & 60 & 26.01 & 25.33 & 25.70 & 2.61 & 1.21 \\
\hline 38 & 2 & 100 & 75 & 32.36 & 32.79 & 33.06 & 1.33 & 2.17 \\
\hline 39 & 2 & 100 & 90 & 40.26 & 40.25 & 40.43 & 0.03 & 0.41 \\
\hline 40 & 2 & 120 & 60 & 34.62 & 33.10 & 33.55 & 4.40 & 3.09 \\
\hline 41 & 2 & 120 & 75 & 39.78 & 40.56 & 40.91 & 1.96 & 2.86 \\
\hline 42 & 2 & 120 & 90 & 49.25 & 48.01 & 48.28 & 2.51 & 1.97 \\
\hline 43 & 2 & 140 & 60 & 40.94 & 40.86 & 41.40 & 0.19 & 1.13 \\
\hline 44 & 2 & 140 & 75 & 47.27 & 48.32 & 48.77 & 2.23 & 3.18 \\
\hline 45 & 2 & 140 & 90 & 57.91 & 55.78 & 56.13 & 3.68 & 3.07 \\
\hline 46 & 2 & 160 & 60 & 48.15 & 48.63 & 49.26 & 1.00 & 2.31 \\
\hline 47 & 2 & 160 & 75 & 57.43 & 56.09 & 56.62 & 2.33 & 1.40 \\
\hline 48 & 2 & 160 & 90 & 64.04 & 63.54 & 63.99 & 0.78 & 0.09 \\
\hline 49 & 2 & 180 & 60 & 57.24 & 56.39 & 57.11 & 1.48 & 0.23 \\
\hline 50 & 2 & 180 & 75 & 64.29 & 63.85 & 64.48 & 0.68 & 0.29 \\
\hline 51 & 2 & 180 & 90 & 70.79 & 71.31 & 71.84 & 0.73 & 1.48 \\
\hline
\end{tabular}


Table 3. Measured and calculated impact forces. Relative errors (continued).

\begin{tabular}{|c|c|c|c|c|c|c|c|c|}
\hline $\begin{array}{c}\text { Exp. } \\
\text { No. }\end{array}$ & $\begin{array}{c}\text { Diameter } \\
{[\mathrm{mm}]}\end{array}$ & $\begin{array}{c}\text { Pressure } \\
{[\mathrm{bar}]}\end{array}$ & $\begin{array}{c}\text { Angle } \\
{[\alpha]}\end{array}$ & $F_{\text {det }}$ & $F_{\text {taguchi }}$ & $F_{\text {full }}$ & \multicolumn{2}{|c|}{ Relative error $\varepsilon_{x}[\%]$} \\
\hline 52 & 2 & 200 & 60 & 64.99 & 64.16 & 64.96 & $F_{\text {Taguchi }}$ & $F_{\text {full factorial }}$ \\
\hline 53 & 2 & 200 & 75 & 71.88 & 71.62 & 72.33 & 0.37 & 0.04 \\
\hline 54 & 2 & 200 & 90 & 79.06 & 79.08 & 79.69 & 0.02 & 0.62 \\
\hline
\end{tabular}

\section{Conclusions}

The purpose of this study is to determine the equation of impact forces produced by water jets in two ways: once using the Taguchi design of experiments and secondly using the full factorial design of experiments.

Using the Taguchi method and full factorial method has conducted an analysis of the variance to determine the influence of parameters and their interactions on the impact force.

In both cases the conclusion was the same: only 3 parameters (diameter, pressure and angle) and two interactions (diameter-pressure, diameter-angle) have an important contribution.

The parameter distance has an insignificant contribution (less to $1 \%$ ) and can be neglected. Further value of distance parameter was set at $50 \mathrm{~mm}$.

Comparing the relative errors between the two equations relative to measured forces can be seen:

- For $\mathrm{F}_{\text {Taguchi }}$ the maximum value of relative error is $11.46 \%$ and for $\mathrm{F}_{\text {full factorial }}$ the maximum value of relative error is $7.98 \%$.

- In generally the values obtained from $\mathrm{F}_{\text {full factorial }}$ are closer to the measured forces.

The advantages of Taguchi method are the reduced number of experiments, reduced costs and reduced time. The disadvantage is that the method is not as accurate like full factorial method.

The advantage of full factorial method is the accurate compare with Taguchi method. The disadvantages of this method are the large number of experiments, the costs of the experiments and more time to perform the experiments.

It is hard to say which method it is better. It depends on the experience of the researcher, on the time and resources, how accurate must be the results.

\section{References}

1. W. F. Adler, The Mechanics of Liquid Impact. Treatise on Materials Science and Technology, (16) editor C.M.Preece, (Academic Press, 127-183, 1979)

2. S. J. Leach, G. L. Walker, Phil. Trans. Roy. Soc. 260, (A), 295-308 (1966)

3. M. Leu, C.P. Meng, E.S. Geskin, L. Tismeneskiy, J. Manuf. Sci. Eng 120 (3), 571-579 (1998)

4. A. Guha, R.M. Barron, R. Balachandar, J. Mater. Process. Technol. 211 (4) 610-618 (2011)

5. A. W. Momber, Hydroblasting and Coating of Stell structures (Oxford: Elsevier Ltd, 2003)

6. N. Medan, Research and Contributions to the Functioning of Cleaning Head-Sewer System, PhD Thesis (Baia Mare, 2014)

7. D.C. Montgomery, Design and analysis of experiments, $8^{\text {th }}$ edition (Wiley, 2013) 